\title{
Postembryonic RNAi in Heterorhabditis bacteriophora: a nematode insect parasite and host for insect pathogenic symbionts Todd A Ciche ${ }^{1}$ and Paul W Sternberg*2
}

\author{
Address: ${ }^{1}$ Department of Microbiology and Molecular Genetics, Michigan State University, 2215 Biomedical Physical Sciences Building, East \\ Lansing, MI 48824, USA and ${ }^{2}$ Mail Code 156-29, California Institute of Technology, 1200 E. California Blvd., Pasadena, CA 91125, USA \\ Email: Todd A Ciche - ciche@msu.edu; Paul W Sternberg* - pws@caltech.edu \\ * Corresponding author
}

Published: 5 September 2007

BMC Developmental Biology 2007, 7:101 doi:10.1/86/147|-213X-7-101
Received: 14 February 2007

Accepted: 5 September 2007

This article is available from: http://www.biomedcentral.com/I47I-2I3X/7/I0I

(c) 2007 Ciche and Sternberg; licensee BioMed Central Ltd.

This is an Open Access article distributed under the terms of the Creative Commons Attribution License (http://creativecommons.org/licenses/by/2.0), which permits unrestricted use, distribution, and reproduction in any medium, provided the original work is properly cited.

\begin{abstract}
Background: Heterorhabditis bacteriophora is applied throughout the world for the biological control of insects and is an animal model to study interspecies interactions, e.g. mutualism, parasitism and vector-borne disease. H. bacteriophora nematodes are mutually associated with the insect pathogen, Photorhabdus luminescens. The developmentally arrested infective juvenile (IJ) stage nematode (vector) specifically transmits Photorhabdus luminescens bacteria (pathogen) in its gut mucosa to the haemocoel of insects (host). The nematode vector and pathogen alone are not known to cause insect disease. RNA interference is an excellent reverse genetic tool to study gene function in $C$. elegans, and it would be useful in $H$. bacteriophora to exploit the $H$. bacteriophora genome project, currently in progress.
\end{abstract}

Results: Soaking LI stage H. bacteriophora with seven dsRNAs of genes whose C. elegans orthologs had severe RNAi phenotypes resulted in highly penetrant and obvious developmental and reproductive abnormalities. The efficacy of postembryonic double strand RNA interference (RNAi) was evident by abnormal gonad morphology and sterility of adult $H$. bacteriophora and $C$. elegans presumable due to defects in germ cell proliferation and gonad development. The penetrance of RNAi phenotypes in $\mathrm{H}$. bacteriophora was high for five genes (87-100\%; Hba-cct-2, Hba-daf-2 I, Hbaicd-I; Hba-nol-5, and Hba-WOIG7.3) and moderate for two genes (usually 30-50\%; Hba-rack-I and Hba-arf-I). RNAi of three additional C. elegans orthologs for which RNAi phenotypes were not previously detected in $C$. elegans, also did not result in any apparent phenotypes in $H$. bacteriophora. Specific and severe reduction in transcript levels in RNAi treated LIs was determined by quantitative real-time RT-PCR. These results suggest that postembryonic RNAi by soaking is potent and specific.

Conclusion: Although RNAi is conserved in animals and plants, RNAi using long dsRNA is not. These results demonstrate that RNAi can be used effectively in $H$. bacteriophora and can be applied for analyses of nematode genes involved in symbiosis and parasitism. It is likely that RNAi will be an important tool for functional genomics utilizing the high quality draft $H$. bacteriophora genome sequence. 


\section{Background}

Heterorhabditis bacteriophora is a rhabditid entomopathogenic nematode (EPN) symbiotic with the enteric bacterium Photorhabdus luminescens, a dangerous liaison lethal to many insect hosts [1]. EPNs are applied globally for the biological control of insects. The nematode is also a potentially powerful animal model to study interspecies interactions such as mutualism, parasitism, and vectorborne disease. Genomics and genetics are available for the symbiont, and because it is a close relative to Caenorhabditis elegans, are being developed for the nematode. In addition, well-studied arthropod models (e.g. Drosophila melanogaster) can be used as hosts [2].

The developmentally arrested infective juvenile (IJ) nematodes exist in soil and transmit an average of $130 \mathrm{P}$. luminescens bacteria in their gut mucosa, sometimes for several months, before locating and infecting a suitable insect host [3]. The IJs search, locate and penetrate the insect exoskeleton or intestine, sometimes by using a buccal tooth, and then regurgitate the bacteria into the haemocoel (Figure 1). The association is an obligate mutualism since both the nematode and bacterium are required for insect pathogenicity.

The nematode is dependent on symbiotic bacteria for insect pathogenicity and nematode growth and reproduction since axenic IJs do not cause insect mortality nor develop and reproduce normally [4]. In contrast, P. luminescens are highly virulent when injected into the insect haemocoel, having an $\mathrm{LD}_{50}<30$ cells for many insect hosts, but are dependent on the IJs for transmission and persistence outside of insect hosts. After the bacteria are regurgitated by the IJs [3], insect mortality rapidly ensues (usually $<48 \mathrm{~h}$ ) and the bacteria grow to high cell densities and produce insecticidal toxins, secondary metabolites to inhibit saprophytic microbes, bacteriophagous nematodes and savaging insects. In addition, the bacteria are required for nematode growth and reproduction $[4,5]$.

Reproduction of $H$. bacteriophora is heterogonic: both automictic hermaphrodites and amphimictic females and males are formed [6]. The IJs are hermaphroditic, but generate automictic and amphimictic progeny that grow and reproduce for several generations on $P$. luminescens, after which, the hermaphroditic IJ stage is formed. The IJs are specifically colonized by $P$. luminescens and transmit the bacteria to new insect hosts.

Heterorhabditis bacteriophora is closely related to C. elegans (Rhabditidae) and can be propagated outside of insect hosts on agar based media and in liquid culture provided that a monoculture of symbiotic $P$. luminescens is present. We sought to further utilize the techniques and knowl- edge of C. elegans to study the interactions between $\mathrm{H}$. bacteriophora, P. luminescens and insects.

One of these techniques is targeted gene silencing by $\mathrm{RNAi}$, a powerful molecular genetic tool to elucidate gene function. In C. elegans, RNAi was originally performed by injecting dsRNA into the body of L4 animals $[7,8]$ and also shown to be effective by soaking $[9,10]$, on lawns of bacteria expressing dsRNA [11] or by expressing dsRNA in C. elegans cells [12]. RNAi by feeding [13,14], soaking [15] and injection [16] are amenable to high throughput methodologies. The dependence of $H$. bacteriophora for symbiotic bacteria for growth and reproduction makes RNAi by feeding problematic. Therefore, we developed a soaking protocol for efficient RNAi in $H$. bacteriophora. Using this protocol we detected highly penetrant and obvious phenotypes in $H$. bacteriophora for seven C. elegans orthologs, previously reported to have highly penetrant and obvious phenotypes in C. elegans. This is the first demonstration of RNAi by soaking in $\mathrm{H}$. bacteriophora, a technique difficult for many nematodes other than C. elegans perhaps due to inefficient uptake of environmental dsRNA [[17], M. Montgomery pers. comm.]. This technique is amenable to high-throughput methodologies and should greatly enhance the analysis of gene function in H. bacteriophora.

\section{Results and discussion}

Optimization of RNAi methodology for $\mathrm{H}$. bacteriophora Since $H$. bacteriophora requires $P$. luminescens for growth and reproduction, one strategy for RNAi might be to express H. bacteriophora dsRNA in Escherichia coli HT115 (DE) delivered while in co-culture with $P$. luminescens. We tested the validity of this approach by determining if highly penetrant ds Cel-pop-1 RNA, retains silencing activity in C. elegans when grown in co-cultures of $P$. luminescens. C. elegans L4 grown on lawns of HT115 expressing ds Cel-pop-1RNA resulted in embryonic lethality (Emb) with $100 \%$ penetrance. However, silencing was abolished when as little as $2 \%$ P. luminescens were added $(0 \% \mathrm{Emb})$ and to a lesser extent in the presence of $2 \%$ Escherichia coli OP50 (data not shown). Therefore, the strategy to deliver dsRNA as a HT110-P. luminescens co-culture was not feasible, presumably due to nucleases produced by $P$. luminescens. We then attempted to use a soaking methodology to deliver dsRNA for RNAi in H. bacteriophora.

Soaking L1 H. bacteriophora in M9 buffer resulted in high lethality $(>90 \%)$. Survival of L1 larvae was improved in Sbasal media and found to be optimal in Ringer's solution buffered with HEPES (pH 6.9). Initial experiments soaking L1 larvae for $24 \mathrm{~h}$ in Ringer's solution sometimes resulted in significant adult sterility. However, using L1s harvested from pure monocultures of $P$. luminescens, the adult nematodes were fertile. Thus, a pure monoxenic cul- 


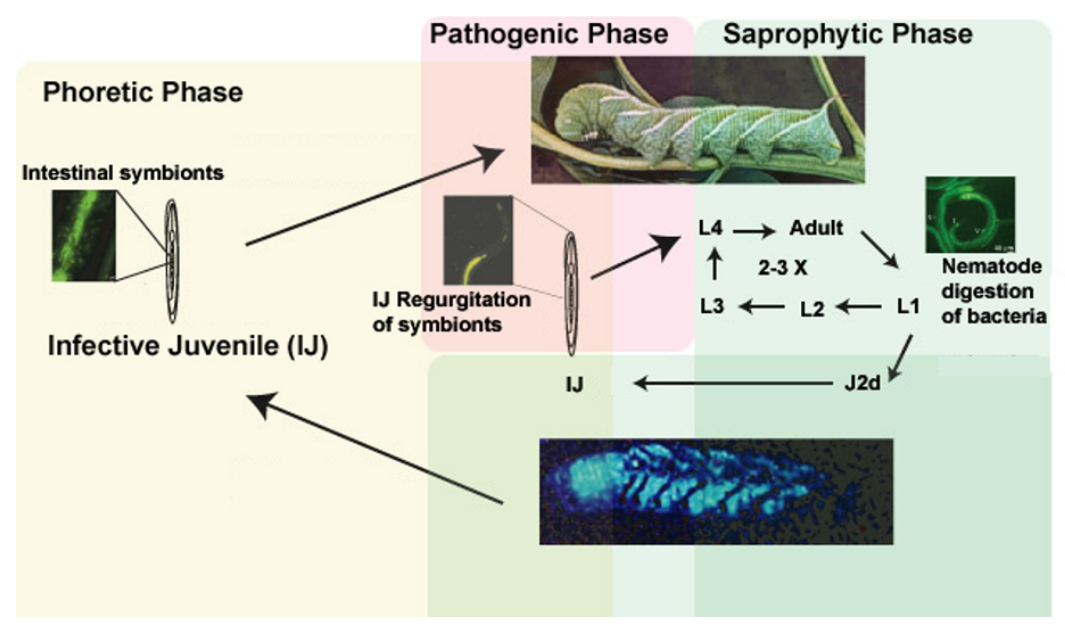

\section{Figure I}

Life-cycle of Heterorhabditis bacteriophora (adapted from [I]). The non-feeding developmentally arrested dauer or infective juvenile (IJ) transmits a monoculture of symbiotic $P$. luminescens (GFP-labelled P. luminescens are shown) to the haemocoel of an insect host, where it regurgitates the bacteria. The bacteria rapidly kill the insect (usually $<48$ ) and grow to high densities allowing nematode growth and reproduction (The lower panel is an image taken from the bioluminescence of the bacteria). The nematodes grow for $2-3$ generations, feeding on $P$. luminescence, after which $\left(\sim 10 \mathrm{~d}\right.$ at $\left.28^{\circ} \mathrm{C}\right) \mathrm{IJs}$ are formed en masse, most transmitting symbiotic $P$. luminescens.

ture of H. bacteriophora-P. luminescens is important for survival and development of the nematodes during and after RNAi.

From 850 EST sequences, kindly communicated by Ann Burnell (National University of Ireland, Maynooth, Ireland), seven orthologs that had obvious and highly penetrant RNAi phenotypes in C. elegans, were chosen for RNAi by soaking in $H$. bacteriophora (Table 1 , see additional file
1). Three other ESTs whose C. elegans orthologs had no discernable RNAi phenotype in C. elegans were also tested.

RNAi by soaking L1s in dsRNA corresponding to portions of Hba-cct-2, Hba-icd-1, Hba-daf-21, Hba-nol-5, HbaW01G7.3, Hba-K04D7.1 and Hba-arf-1 were successful as evidenced by sterility, defective gonad development and germline proliferation in adult animals (Table 2, Figure 2). L1s soaked in Ringer's solution with no dsRNA added or dsRNA corresponding to portions of $\mathrm{Hba-mrp-4,Hba-}$

Table I: Candidate $\boldsymbol{H}$. bacteriophora genes for RNAi gene silencing

\begin{tabular}{|c|c|c|c|c|}
\hline GeneA $^{A}$ & Predicted Function ${ }^{B}$ & C. e. Ortholog & \%Identity, lengthc & C. elegans Phenotypes ${ }^{D}$ [ref] \\
\hline Hba-cct-2 & T-complex chaperonin & T2IBI0.I (Cel-cct-2) & 79,357 & Emb, Ste $[13,14]$, Pch, Pvl, [I4], Lva [13] \\
\hline Hba-daf-2I & Hsp-90 chaperonin & C47E8.5 (Cel-daf-2I) & 79,804 & Emb, Ste $[3 \mid]$ \\
\hline Hba-icd-I & BTF3 transcription factor Anti-apoptotic & C56CI0.8 (Cel-icd-I) & 75,529 & $\begin{array}{l}\text { Emb }[13,|14,3|], \text { Gro }[13,14,15], \text { Stp } \\
{[14,15], \text { Bmd, Clr, Sck [13], Unc }[14]}\end{array}$ \\
\hline Hba-nol-5 & Ribosome biogenesis Nop58p/Nop5p & WoIBII.3 (Cel-nol-5) & 74,634 & $\begin{array}{l}\text { Lva }[|4,3|, 53], \text { Emb, Lva [3।,53], Gro, } \\
\text { Muv, Pvl, Sle, Stp, [3।] }\end{array}$ \\
\hline Hba-W0IG7.3 & RNA polymerase subunit $L$ & W0IG7.3 (Cel-WOIG7.3) & 80,81 & $\begin{array}{l}\text { Emb }[13,|4,| 5,3 \mid], \text { Gro }[14,3 \mid], \text { Ste, Stp } \\
{[3 \mid], \text { Pvl [14], Lva [15] }}\end{array}$ \\
\hline Hba-rack-I & $\mathrm{G}$ protein $\beta$-like subunit & K04D7.I (Cel-rack-I) & 75,441 & Gro $[13, \mid 4]$, Emb, Egl $[13]$, Slu [14] \\
\hline Hba-arf-I & ADP-ribosylating factor & B0336.2 (Cel-arf-I) & 75,219 & $\begin{array}{l}\text { Emb }[13,14,36], \text { Unc }[13,14], \text { Pvl, Rup, Ste } \\
{[13], \text { Gro }[14]}\end{array}$ \\
\hline Hba-ben-I & $\beta$-tubulin, benomyl sensitivity & C54C6.2 (Cel-ben-I) & 78,518 & no phenotype reported \\
\hline Hba-mrp-4 & Mrp-I multidrug resistance family & F2IG4.2 (Cel-mrp-4) & 61,468 & no phenotype reported \\
\hline Hba-nhr-47 & nuclear hormone receptor & C24G66.4 (Cel-nhr-47) & 65,269 & no phenotype reported \\
\hline
\end{tabular}

A Based on ESTs, see methods for accession \#'s.

$B$ Based on Wormbase gene description for C. elegans ortholog.

C Based on BLASTN analysis in Wormbase. growth, Muv = multivulva, Pch = patchy coloration, Pvl = protruded vulva, Sck = sick, Sle = slow embryonic development, Slu $=$ sluggish, Ste $=$ sterile, Stp $=$ sterile progeny, Unc $=$ uncoordinated 
ben-1, and Hba-nhr-47, resulted in adults with normal fertility, gonad morphology and oocyte formation (Table 2, Figure 2).

\section{RNAi of $\mathrm{H}$. bacteriophora}

The C. elegans cct-2 (T21B10.1) gene encodes a component of eukaryotic T-complex chaperonin (CCT or TRiC)[18]. CCT is a group II chaperonin of similar structure to the prokaryotic GroEL chaperonin, but found only in Eukarya and Archea [19]. CCT/TRiC is required to fold actin [20], tubulin [21], cyclin E1 [22] and also $10 \%$ of newly synthesized cytoplasmic proteins [23], including proteins with WD40 domains [24]. In C. elegans, mec-3 independent expression of $c c t-2$ touch receptors has also been demonstrated, suggesting a role for CCT in touch receptor function, possibly through microtubule assembly [25].
In C. elegans, published RNAi experiments of $c c t-2$ resulted in embryonic lethal (Emb) and sterile (Ste) phenotypes $[13,14]$ and sometimes a protruding vulva (Pvl)(Table 1)[14]. RNAi by feeding L1 C. elegans with bacteria expressing ds Cel-cct-2 RNA resulted in a highly penetrant Ste phenotype with Pvl also observed (Table 2). Soaking L1 $H$. bacteriophora in ds Hba-cct-2 RNA resulted in a highly penetrant $(100 \%$ in 4 trials, $96 \%$ and $94 \%$ in two other trials) Ste phenotype (Table 2). The cause of sterility was likely due to defective gonad development and absence of germ cells (Figure 2E, F). Mature H. bacteriophora hermaphrodites which lack gonads have an empty or transparent appearance due to a void space in the pseudocoelom normally occupied by the gonad (Figure 2E, F). Both C. elegans and H. bacteriophora treated with their respective ds $c c t-2$ RNA were sterile and had abnormal gonads, although only C. elegans had a protruded vulva

Table 2: H. bacteriophora and C. elegans RNAi Phenotypes

\begin{tabular}{|c|c|c|c|c|c|c|}
\hline \multirow[b]{2}{*}{$\begin{array}{c}\text { Nematode } \\
\text { Gene } \\
\text { (Phenotype) }\end{array}$} & \multicolumn{6}{|c|}{ Trial } \\
\hline & I \%Pen.(n)A & 2 \%Pen.(n) & 3 \%Pen.(n) & 4 \%Pen.(n) & 5 \%Pen.(n) & 6 \%Pen.(n) \\
\hline
\end{tabular}

\section{H. bacteriophora ${ }^{B}$}

\begin{tabular}{lllllll}
\hline (-)water (Ste) & $0(49)$ & $0(17)$ & $0(20)$ & $0(39)$ & $0(40)$ & $0(30)$ \\
Hba-cct-2 & $100(34)$ & $100(36)$ & $100(16)$ & $96(24)$ & $94(64)$ & $100(34)$ \\
Hba-daf-2I & $100(36)$ & $100(19)$ & $100(30)$ & $92(24)$ & $82(34)$ & $87(47)$ \\
Hba-icd-I & $100(3 I)$ & $100(38)$ & $87(15)$ & $100(15)$ & $98(40)$ & $98(40)$ \\
Hba-nol-5 & $95(39)$ & $100(32)$ & $100(4 I)$ & $93(30)$ & $57(28)$ & $72(32)$ \\
Hba-WOIG7.3 & $95(39)$ & $100(34)$ & $95(39)$ & $100(33)$ & $83(47)$ & $86(49)$ \\
Hba-rack-I & $31(39)$ & $82(22)$ & $28(25)$ & $61(28)$ & $10(39)$ & $33(33)$ \\
Hba-arf-I & $50(32)$ & $67(15)$ & $47(15)$ & ndC & nd & nd \\
Hba-ben-I & $0(48)$ & $38(21)$ & $11(36)$ & $0(45)$ & $0(42)$ & $0(33)$ \\
Hba-nhr-47 & nd & $12(17)$ & $3(36)$ & nd & nd & nd \\
Hba-mrp-4 & $0(57)$ & $10(21)$ & $0(26)$ & nd & nd & nd
\end{tabular}

C. elegans ${ }^{\mathrm{D}}$

\begin{tabular}{|c|c|c|c|c|c|c|}
\hline Cel-cct-2 (Pvl) & $83(86)$ & $7 I(97)$ & $53(92)$ & nd & nd & nd \\
\hline (Ste) & $100(86)$ & $100(97)$ & $100(92)$ & nd & nd & nd \\
\hline Cel-icd-I (Pvl) & $81(118)$ & $86(114)$ & nd & nd & nd & nd \\
\hline (Ste/Stp) & $100(118)$ & $100(114)$ & nd & nd & nd & nd \\
\hline Cel-W0IG7.3 (Pvl) & $10(94)$ & $9(64)$ & $12(69)$ & nd & nd & nd \\
\hline (Ste) & $100(94)$ & $100(64)$ & $<100(>50)$ & nd & nd & nd \\
\hline (Egl, Stp) & nd & nd & few & nd & nd & nd \\
\hline Cel-nol-5 (Pvl) & $68(94)$ & $64(98)$ & nd & nd & nd & nd \\
\hline (Ste) & $100(94)$ & $100(98)$ & nd & nd & nd & nd \\
\hline Cel-rack-I (Pvl) & $19(66)$ & $4(80)$ & $3(72)$ & nd & nd & nd \\
\hline (Ste) & $100(66)$ & $<100(>50)$ & $<100(>50)$ & nd & nd & nd \\
\hline (Egl, Stp) & 0 & Few & few & nd & nd & nd \\
\hline Cel-ben-I & $w t^{E}(>50)$ & wt $(>50)$ & wt $(>50)$ & nd & nd & nd \\
\hline
\end{tabular}

A Percent penetrance (\% Pen.), number of worms examined ( $n$ ).

B Number of sterile adult female or hermaphrodites with defective gonads from RNAi by soaking, see methods for details.

CNot determined

D Postembryonic phenotypes from RNAi by feeding, see methods for details.

E Indistinguishable from wt. 


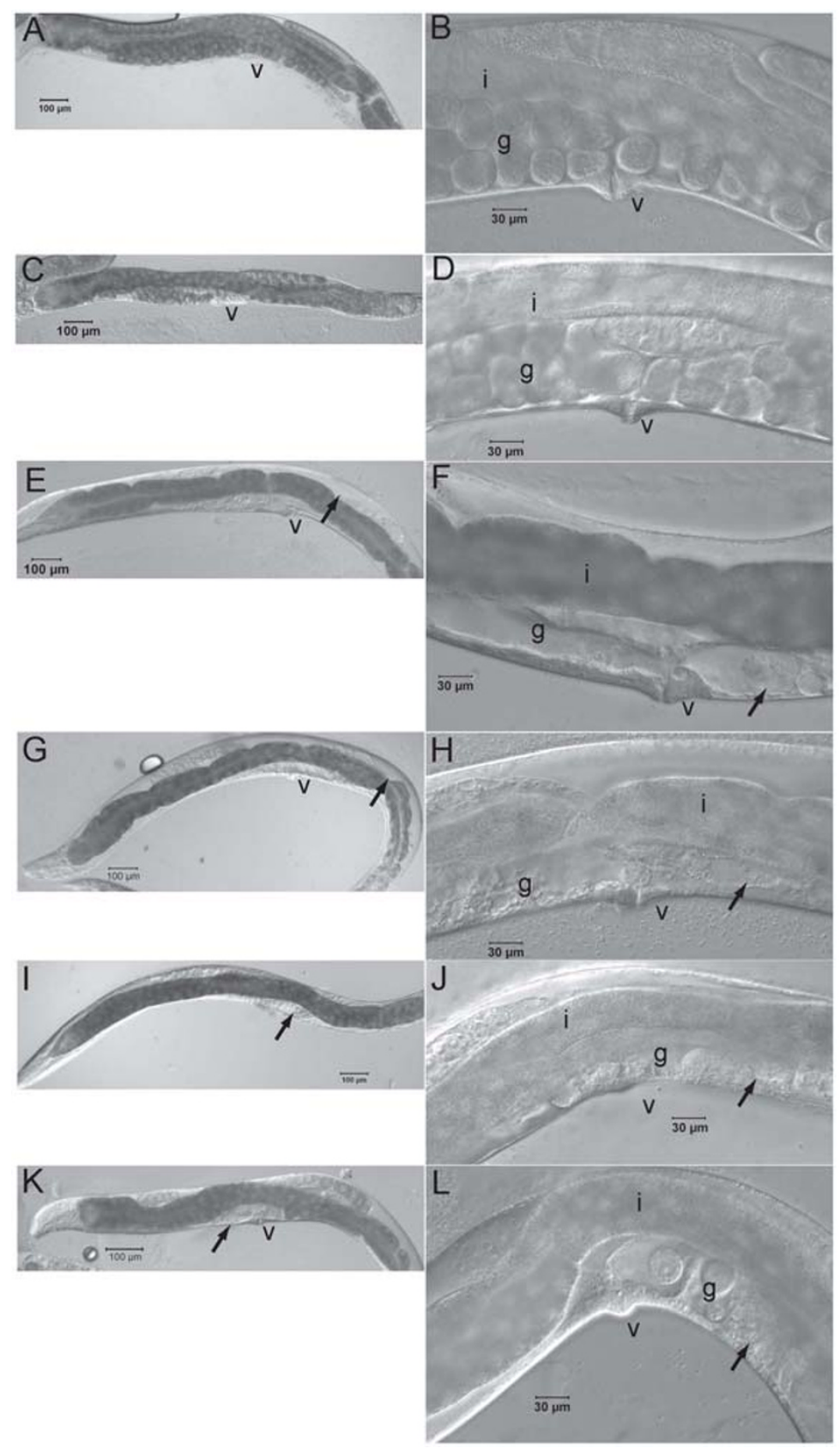

\section{Figure 2}

Postembryonic RNAi phenotypes of $\boldsymbol{H}$. bacteriophora. Heterorhabditis bacteriophora adult hermaphrodites $80-96 \mathrm{~h}$ after soaking LIs with A., B. no dsRNA added. C., D. ds Hba-ben-I RNA, E., F. ds Hba-cct-2 RNA, G., H. ds Hba-daf-2 I RNA, I., J. ds Hba-icd-I RNA, and K., L. ds Hba-nol-5 RNA. v = vulva, $\mathrm{i}=$ intestine, $\mathrm{g}=$ gonad, ab = abnormal gonad. 
(Table 2). The comparable penetrances of these phenotypes suggest that RNAi by soaking in $H$. bacteriophora is nearly as efficient as by feeding in C. elegans.

The C. elegans daf-21(C47E8.5) gene encodes a member of the Hsp90 family of molecular chaperones important for maturation of signal transduction kinases in neurons involved in odorant perception and required for larval development [26]. Hsp90 is also expressed in the gonad and required for germline development [27], but is also expressed somatically during stress as part of the age-1 related aging regulon [28-30]. A published RNAi experiment of daf-21 in C. elegans resulted in Emb and Ste phenotypes [31]. The post-embryonic phenotype of $H$. bacteriophora treated with ds Hba-daf-21 RNA resulted in sterile animals with abnormal gonad morphology (Figure 2G, H). Like RNAi of Hba-cct-2, RNAi of Hba-daf-21 was highly penetrant (Table 2, 100\% for 3 trials and 92\%, $82 \%, 87 \%$ each for single trials).

The C. elegans icd-1 (C56C10.8) gene encodes the beta subunit of nascent polypeptide associated complex $(\beta N A C)$ associated with the mitochondrial membrane and an inhibitor of apoptosis [32]. Published RNAi experiments of $i c d-1$ in C. elegans resulted in Emb, slow growth and Ste phenotypes (Table 1) [13-16]. We detected highly penetrant Ste, Pvl, and defective gonad morphology phenotypes by feeding C. elegans ds-icd-1 (Table 2, Figure 3). Postembryonic RNAi of $H$. bacteriophora resulted in Ste phenotype due to an abnormal gonad with little germ cell proliferation (Figure 2I, J). This phenotype was highly penetrant (Table 2, 100\% Ste in 3 trials, $98 \%$ in 2 trials, and $87 \%$ in one trial). We did not observe apoptosis in $H$. bacteriophora, and we were unable to generate sufficient males to observe defects in male tale rays, phenotypes observed in C. elegans [32].

The C. elegans W01B11.3 gene, recently named nol-5 (Jonathan Hodgkin, personal communication), is predicted to encode an ortholog of the ribosome biogenesis protein Nop58p/Nop5p and is likely essential for information processing. Published RNAi experiments of Celnol-5 usually resulted in larval arrest and Emb phenotypes, with multivulva, protruding vulva, slow growth, maternal sterility and sterile progeny phenotypes also observed [14,31]. RNAi by feeding ds Cel-nol-5 RNA resulted in Pvl, Ste with abnormal gonad development phenotypes (Table 2, Figure 3E, F). RNAi of Hba-nol-5 in $H$. bacteriophora resulted in a Ste phenotype with abnormal gonads (Figure $2 \mathrm{~K}, \mathrm{~L}$ ), which was highly penetrant (Table 2, 100\% two trials, 95\%, 93\%, 72\% and 57\% in four other trials).

The C. elegans gene W01G7.3, like Cel-nol-5, is likely essential for information processing since it is predicted to encode subunit L of RNA polymerase. RNAi of W01G7.3 in C. elegans resulted in Emb phenotype with several other growth defects observed (Table 1) [13-15,31]. RNAi of Hba-W01G7.3 resulted in Ste phenotype with an abnormal gonad, likely due to the essential role for this protein

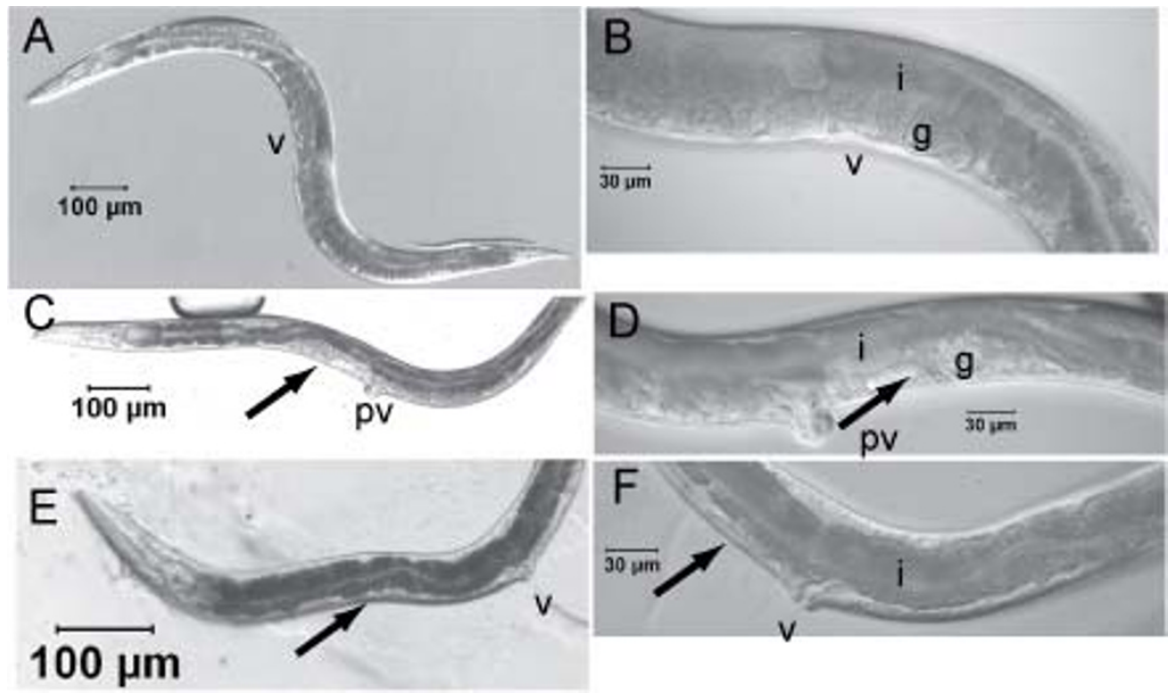

\section{Figure 3}

Postembryonic RNAi phenotypes of C. elegans. Caenorhabditis elegans adult hermaphrodites of $72-80 \mathrm{~h}$ after LIs were placed on E. coli HTI 10 expressing A., B. dsGFP RNA, C., D., ds Cel-icd-I RNA, E., F., and ds Cel-nol-5 RNA. v = vulva, pv = protruding vulva, $\mathrm{i}=$ intestine, $\mathrm{g}=$ gonad. Arrow denotes abnormal gonad. 
in cell viability and division (Table 2). This phenotype was highly penetrant, with $>83 \%$ of adults being sterile with abnormal gonads (Table 2).

The C. elegans rack-1 (K04D7.1) gene is predicted to encode the homolog of mammalian receptor of activated C kinase. Published RNAi experiments of Cel-rack-1 in C. elegans resulted in less obvious and penetrant phenotypes than those described above: Emb, slow growth, egg laying defect, aldicarb resistance, and larval lethality (Table 1) $[13,14]$. RNAi of Hba-rack-1 resulted in $10-82 \%$ of animals with a Ste phenotype and abnormal gonad development (Table 2, Figure 2). Thus, lower penetrances were observed using ds-rack-1 RNA for both $H$. bacteriophora and C. elegans.

The C. elegans arf-1 (B0336.2) gene encodes a predicted ADP-ribosylating factor (ARF). ARFs are known to regulate membrane trafficking and the actin cytoskeleton, phospholipase D1 and phosphatidylinositol 4-phosphate 5-kinase [33]. RNAi of Cel-arf-1 resulted in Emb and a variety of other defects (Table 1) [14,15]. RNAi of Hba-arf1 resulted in a Ste phenotype with abnormal gonads in $50 \%, 67 \%$ and $47 \%$ in each of three trials (Table 2).

The C. elegans ben-1 (C54C6.2) gene, also known as tbb-1, encodes the beta subunit of tubulin, which when disrupted, results in resistance to benzimidizole [34]. RNAi of ben-1 in C. elegans usually resulted in no observed defect $[13,35,36]$ although Emb, abnormal post-embryonic development, larval arrest and larval development were sometimes observed $[13,35,36]$. RNAi of Hba-ben-1 in $H$. bacteriophora usually resulted in no observable defect, although a Ste $(38 \%, 11 \%)$ phenotype was observed in two experiments.

The C. elegans mrp-4 (F21G4.2) gene is predicted to encode a multidrug-resistance associated (mrp-1 type) protein related to human cystic fibrosis transmembrane conductance regulator, CFTR. RNAi of $m r p-4$ in C. elegans resulted in no observed phenotype $[13,16]$. Since the $P$. luminescens symbiont of $H$. bacteriophora produces several known secondary metabolites, such as hydroxystilbene antibiotics, anthraquinone pigments [37] and a photobactin siderophore [38], it is possible that $H$. bacteriophora multidrug-resistance associated proteins might be involved in exporting these secondary metabolites. RNAi of Hba-mrp-4 in H. bacteriophora resulted in no observed defect in two trials and $10 \%$ sterility in one trial (Table 2). It is likely that $H$. bacteriophora, like C. elegans [39], has several multidrug-resistance associated proteins and this redundancy might be responsible for the weak phenotype from RNAi of Hba-mrp-4. Alternatively, other resistance mechanism might be employed to resist secondary metabolites produced by $P$. luminescens.
The C. elegans nhr-47 (C24G66.4) gene is predicted to encode a nuclear hormone receptor and is induced upon worm exposure to estradiol [40]. Published RNAi experiments of Cel-nhr-47 in C. elegans resulted in no observed phenotype $[13,16,35]$. Similarly, RNAi of Hba-nhr-47 in $H$. bacteriophora usually resulted in no observed phenotype, although $12 \%$ and $3 \%$ Ste animals were observed (Table 2, Figure 2).

\section{Quantification of RNAi by Real-time RT-qPCR}

To determine the extent of RNAi silencing in H. bacteriophora, quantitative real-time RT-qPCR experiments were performed. Message levels of Hba-cct-2 and Hba-nol-5 were quantified relative to $\mathrm{Hba}$-ben-1 when treated with the specific or unspecific dsRNA (i.e. for $\mathrm{Hba}-\mathrm{cct}-2$ and Hba-nol-5, RNAi using ds Hba-nol-5 and ds Hba-cct-2 RNAs were used, respectively). Relative amounts of mRNA were determined using the $\Delta \Delta \mathrm{C}_{\mathrm{t}}$ method. RNAi of Hba-cct-2 resulted in mRNA levels $5.8 \times 10^{-3}$ and $8.5 \times 10^{-6}$ relative to the nonspecific dsRNA control. RNAi of Hba-nol-5 resulted in mRNA levels $2.6 \times 10^{-3}$ and $7.1 \times 10^{-2}$ relative to the nonspecific dsRNA control. RNAi of Hba-ben-1 resulted in mRNA levels $1.6 \times 10^{-2}$ and $9.9 \times 10^{-4}$ relative to two nonspecific dsRNA controls: $\mathrm{Hba}$-nol-5 in an $\mathrm{Hba}$ $c c t-2$ RNAi experiment or Hba-cct-2 in a Hba-nol-5 experiment, respectively. From these data we conclude that RNAi by soaking in $H$. bacteriophora is potent and specific.

\section{RNAi treated $\mathrm{H}$. bacteriophora are normal in symbiotic host-bacterial interactions}

One of our goals for developing RNAi in H. bacteriophora is to use this technique along with imminent high quality draft ( $6 \times$ coverage) H. bacteriophora genome sequence (R. Wilson, personal communication), to identify genes involved in symbiotic host-bacterial interactions. Many of the genes silenced have essential functions in the nematode and we sought to determine if these RNAi treated animals have defects in symbiotic host-bacterial interactions. RNAi treated worms for all 10 genes described above were reared on GFP-labeled P. luminescens and observed for bacterial colonization in the adult nematode intestine. No difference was seen in the presence of GFP-labeled P. luminescens in the intestines of RNAi treated and untreated worms (see additional file 2). This observation suggests that specific genes involved in symbiotic host-bacterial interactions can be identified using RNAi.

\section{Conclusion}

Gene silencing by RNAi is a powerful reverse genetic tool to study gene function. Although, RNAi using long dsRNA is robust in C. elegans, it is inefficient in many other nematodes. The robustness of RNAi in C. elegans can be partially attributed to the systemic RNAi defective gene, Celsid-1, involved in the transport of long dsRNA $[41,42]$ and recently, Cel-sid-2 required for efficient transport of 
dsRNA in the C. elegans intestine [17]. Recently, the systemic RNAi defective gene, $\mathrm{Hba}$-sid-1, was identified in $H$. bacteriophora [43] which might partially explain the obvious phenotypes and high penetrances of RNAi in $\mathrm{H}$. bacteriophora. Because the nematode egg yolk is synthesized by intestinal cells, it is possible that the Ste and gonad defective phenotypes are caused by RNAi of only the nematode intestinal cells. However, the low amounts of transcript levels detected in L1s following RNAi suggests that RNAi is nearly systemic. This hypothesis could be tested, in principle, by performing RNAi on muscle tissue, for example by silencing the unc-22 gene conferring a twitching phenotype to C. elegans [44]. Attempts to use degenerate primers to amplify Hba-unc-22 were not successful and Hba-unc-22 has not been found in existing H. bacteriophora EST datasets. After the completion of the H. bacteriophora genome, this and many other RNAi experiments will be performed.

This study demonstrates that RNAi by soaking is an efficient methodology for gene silencing in H. bacteriophora which can be applied to study many aspects of the unique biology including parasitism and mutualism. One limitation to this methodology is the development of RNAi treated nematodes to adults versus the infective juvenile stage, the later which transmits the symbiotic bacteria and are insect parasitic. The lack of IJ development from RNAi treated larvae is likely due to the large amount of food signal provided by the confluent lawn of P. luminescens on which the L1s are placed. The density of L1 larvae might also influence the development of the L1 larvae to the IJ stage. The severe and highly penetrant phenotypes observed here suggests that RNAi will be a useful tool to study gene function in $H$. bacteriophora, i.e. related to symbiont transmission, parasitism, sex determination, stress resistance and infective juvenile formation.

More generally, mixed results concerning the efficiency of RNAi have been reported in several clades of parasitic nematodes [45]. Problems encountered using RNAi in parasitic nematodes includes non-target effects of dsRNA, variable efficiencies of RNAi with regard to the target gene silenced and dsRNA preparation, and in vitro cultivation. These problems appear to be less of a concern for $\mathrm{H}$. bacteriophora due to the high specificity and penetrances of RNAi. In the potato cyst nematode Globodara padilla, RNAi of neuronal FMRF amide-like peptides was surprisingly robust [46]. The results reported here are promising to the applicability of RNAi to study gene function in $H$. bacteriophora. However, further refinements of the RNAi methodology are expected when targeting diverse genes expressed in different tissues, when applied to nematodes of different developmental stages and when applied to larger gene sets.

\section{Methods \\ Strains and growth conditions}

Heterorhabditis bacteriophora strain TTO1 was kindly provided by Ann Burnell (National University of IrelandMaynooth). Photorhabdus luminescens subsp. laumondii were isolated from IJs that were surfaced sterilized for 5 min in $2 \%$ commercial bleach ( 12\% sodium hypochlorite) and allowed to release the bacteria on 2\% Proteose Peptone \#3 (PP3)(Difco, Detroit, MI) agar. Glycerol stocks ( $25 \% \mathrm{vol} / \mathrm{vol}$ sterile glycerol) of the bacterium were stored at $-80^{\circ} \mathrm{C}$. The nematodes were cryopreserved as described previously [47] and maintained by infecting Greater Waxmoth larvae, Galleria mellonella (Rainbow Mealworms, Compton, CA) or propagated on lawns of symbiotic bacteria as follows: the primary phase variant of $P$. luminescens was grown overnight at $28^{\circ} \mathrm{C}$ in $3 \mathrm{ml}$ of PP3 after which 50 (MICRO) ul were spread on NA+chol (1.5× Nutrient Broth, 1.5\% agar (Difco, Detroit, MI) and $10 \mu \mathrm{g} /$ $\mathrm{ml}$ cholesterol), the inoculated plates were incubated at $28^{\circ} \mathrm{C}$ overnight, after which 50-100 surface sterilized IJs were added. The nematode cultures were grown at $28^{\circ} \mathrm{C}$ and eggs were collected $\sim 86$ h or IJs $\sim 10 \mathrm{~d}$ after inoculation. An inbred line, M31e, was obtained by self-fertilizing the hermaphrodites for 13 generations by placing single IJs onto NA+chol containing a lawn of $P$. luminescens and inoculating new cultures with single IJ offspring, a process repeated 13 times.

Caenorhabditis elegans N2 were maintained on E. coli OP50 seeded NGM agar as previously described [48].

\section{Generation of dsRNA}

A dataset of approximately 650 expressed sequence tags (ESTs) obtained from $H$. bacteriophora HP88 IJs recovered on lawns of symbiotic P. luminescens was kindly provided by Ann Burnell. The EST dataset was analyzed for the presence of C. elegans orthologs by BLASTX analysis [49] and for gene function and RNAi phenotypes using gene annotations and WormBase [50]. Seven ESTs were chosen that had severe RNAi phenotypes in C. elegans (Hba-cct-2, Hbaicd-1, Hba-daf-21, Hba-nol-5, Hba-W01G7.3, HbaK04D7.1, Hba-arf-1) and one potentially involved in symbiosis (Hba-mrp-4), potentially conferring resistance to benomyl (Hba-ben-1) and a nuclear hormone receptor (Hba-nhr-47) (Table 1, see additional file 1). Oligonucleotide primers were designed using the EST sequence and Primer3 [51]. Large introns were avoided by aligning the EST sequence with the $C$. elegans genome and using the gene structure content of WormBase. The T7 RNA polymerase promoter sequence taatacgactcactatagggaga (T7) was added to each of the 5' ends of the PCR primers for in vitro transcription to generate dsRNA. The primer sequences are: Hba-cct-2T7f, (T7)cagccaaagaggatggagaa; Hba-cct-2T7r, cctccgagaacaagtgcaag; Hba-daf-21T7f, (T7)cgagaaattgccgaagata; Hba-daf-21T7r, (T7)tggcaactcca- 
gaccttctt; Hba-icd-1T7f, (T7)agggaactccacggagaaag; Hbaicd-1T7r, (T7)tcggcctttgtctcattctt; Hba-nol-5T7f, (T7)ggagctagagcagccatacg; Hba-nol-5T7r, (T7)tgtgcaggctgtatcacttc; Hba-W01G7.3T7f, (T7)aagttcggccatcaaatcag; Hba-W01G7.3T7r, (T7)caaaggttcctaacgctgct; HbaK04D7.1T7f, (T7)ggacaattcgctcttctgg; Hba-K04D7.1T7r, (T7)agcgatccatcaggtgaaac; Hba-arf-1T7f, aactgggcgaaatcgttact; Hba-arf-1T7r, ggcagcattcatagcattagg; Hba-ben-1T7f, (T7)aaatggcggcaagtatgttc; Hba-ben-1T7r, (T7)gaaggaacgacggaaaatga; Hba-mrp-4T7f, (T7)cggtcgagagtcaatacaagg; Hba-mrp-4T7r, (T7)gccggggtaatgttgaatg; Hba-nhr-47T7f, (T7)cgatgcagctagtcaacgaa; Hba-nhr-47T7r, (T7)ggcctaattcctaacgcagtc.

Genomic DNA was purified from $H$. bacteriophora IJs collected from $P$. luminescens containing NA+chol plates using a modified CTAB/phenol extraction protocol [52] after which bacterial DNA was digested with DpnI (New England Biolabs, Bedford, MA). 100-200 ng of template was added to a PCR reaction containing $20 \mathrm{pM}$ of each primer, in a $50 \mu \mathrm{l}$ vol using the standard reaction provided for Taq (Promega, Madison, WI). The PCR condition used was: $1.94^{\circ} \mathrm{C}$ for $3 \mathrm{~min}, 2.94^{\circ} \mathrm{C} 45 \mathrm{sec}, 3.57^{\circ} \mathrm{C} 30 \mathrm{sec}, 4$. $72^{\circ} \mathrm{C} 45 \mathrm{sec}, 5$. repeat steps $2-430 \times$ then $6.72^{\circ} \mathrm{C} 10 \mathrm{~min}$. The PCR reactions were analyzed for a single band of predicted size on a $1.2 \%$ agarose gel. $5 \mu$ l of the PCR reaction was then used directly for in vitro transcription using the Megascribe T7 kit (Ambion, Austin, TX) or T7 RiboMax (Promega) according to the instructions provided, except the transcription reactions were incubated for $>6 \mathrm{~h}$ at $37^{\circ} \mathrm{C}$. The DNA templates were removed by DNAse treatment and then dsRNA precipitated by adding $1 / 10 \mathrm{vol}$. of $5 \mathrm{M}$ ammonium acetate and 2.5 vol. of $100 \%$ ethanol for $>1 \mathrm{~h}$ at $4^{\circ} \mathrm{C}$. The precipitated dsRNA was centrifuged for $30 \mathrm{~min}$ at $16,000 \times g$ and then washed with $70 \%$ ethanol prepared in RNAse free water. After air drying for $5 \mathrm{~min}$, the pellet was dissolved in $25 \mu$ l of RNAse free water. The quality of the transcribed RNA was determined by running $1 \mu \mathrm{l}$ on a $1.2 \%$ agarose gel and quantified $\left(\mathrm{A}_{260}\right)$ using a NanoDrop (Nanodrop Technologies, Wilmington, DE).

\section{RNAi of $\mathbf{H}$. bacteriophora}

Heterorhabditis bacteriophora eggs were harvested from NA + chol. containing $P$. luminescens usually $82-86 \mathrm{~h}$ after the addition of 50-100 IJs when grown at $28-29^{\circ} \mathrm{C}$. Washing 1-2 week old IJs three times in $15 \mathrm{ml}$ of Ringer's solution $\left(100 \mathrm{mM} \mathrm{NaCl}, 1.8 \mathrm{mM} \mathrm{KCl}, 2 \mathrm{mM} \mathrm{CaCl}_{2}, 1 \mathrm{mM} \mathrm{MgCl}_{2}\right.$, 5 mM HEPES pH 6.9) improved the synchrony of IJ recovery. At this time most of the eggs were at the pretzel stage of embryonic development. The eggs were harvested by washing the plates $3 \times$ with $2 \mathrm{ml}$ of sterile Ringer's solution and bacteria removed by filtering on a $10 \mu \mathrm{m}$ TCTP membrane (Millipore, Billerica, MA) with a gentle vacuum applied. Eggs and adult hermaphrodites were washed 3 times with $10 \mathrm{ml}$ of Ringer's solution after which eggs were purified from hermaphrodites by their different settling rates. The eggs were concentrated by centrifugation, $2,000 \times \mathrm{g}$ for $1-2 \mathrm{~min}$ and resuspended in Ringer's to a concentration of $\sim 5$ eggs per $\mu \mathrm{l} .4 \mu \mathrm{l}$ of $5-7.5 \mathrm{mg} / \mathrm{ml}$ dsRNA was then added to eggs at total volume of $20 \mu \mathrm{l}$. The eggs hatch in the dsRNA solution while they are incubated for $>24 \mathrm{~h}$ at $28^{\circ} \mathrm{C}$. The resulting L1s were then placed on 18-24 h lawns of $P$. luminescens on NA+chol plates. Postembryonic abnormalities caused by the dsRNA were observed 2-5 days post RNAi treatment.

\section{Quantification of RNAi by Real-time RT-qPCR}

RNAi was performed as described above except 150-250 L1s were soaked with $4 \mathrm{ul}$ of $5-7.5 \mathrm{mg} / \mathrm{ml}$ dsRNA in a total volume of $15 \mu \mathrm{l}$. After $24 \mathrm{~h}$, the L1s were washed $3 \times$ in Ringer's solution. The RNA was extracted by adding 500 ul Trizol (Invitrogen, Carlsbad, CA) and stored at $-80^{\circ} \mathrm{C}$ before extracting according to the manufacturer's instructions. 80-100 ng total RNA treated with 10 U DNAse I for $15 \mathrm{~min}$ at $37^{\circ} \mathrm{C}$. The following primers were used for RTqPCR where one of the primers lies outside the dsRNA used for RNAi: $\mathrm{Hba}$-nol-5RTfor: gtgagatcagtcgagcacca, $\mathrm{Hba}$ nol-5RTrev: cggaggagatcgagtcaaag, Hba-ben-1RTfor: tcatttcggatgaacatgga, Hba-ben-1 RTrev: ggacggaatagcagtccaaa, Hba-cct-2 RTfor: acttcctggtatgtatcagcc, Hba-cct-2 RTrev: gccataactccagcatccgc. 50 ng of total RNA was reverse transcribed using, ThermoScript Reverse Transcriptase (Invitrogen) according to the Manufacturer's instruction, $56^{\circ} \mathrm{C}$ annealing temperature, using antisense primers. Realtime RT-qPCR was performed according to the manufacturer's instructions using Syber Green PCR Master Mix (Applied Biosystems Incorporated, Foster City, CA) performed using a ABI Prism 7900HT Sequence Detection System located at the Michigan State University Research Technology Support Facility. Using Hba-ben-1 as an internal standard, Hba-cct-2 and Hba-nol-5 mRNAs were quantified either in RNAi experiments using specific dsRNA or the unspecific dsRNA corresponding to the other gene (i.e. Hba-cct-2 mRNA treated with ds Hba-nol-5 RNA). Non-RT samples were used as negative controls. The experiments were repeated twice.

\section{RNAi by feeding of C. elegans}

RNAi by feeding was done as published [13], except that eggs were harvested by alkaline hypochlorite lysis of gravid hermaphrodites and added to the HT115 expressing dsRNA. The following HT115(DE3) clones expressing dsRNA in the feeding vector L440 were obtained from the Ahringer RNAi feeding library : pop-1, I-1K04; cct-2, II6O12; icd-1, II-5I03; arf-1, III-3A13; nol-5, I-1O18; W01G7.3, II-9A23; K04D7.1, IV-5K04; ben-1, III-1F10; $m r p-4, \mathrm{X}-1 \mathrm{E} 23$. Sterility of adults, abnormal gonad development and protruding vulva phenotypes were scored 
72-80 h after eggs were placed on dsRNA expressing bacteria.

\section{Accession numbers}

The accession numbers (Genbank, dbEST) for H. bacteriophora ESTs used in this study are: EE724174 (Hba-cct-2); EE724171-EE724173 (Hba-daf-21); EE724162, EE724228 (Hba-icd-1); EE724163-EE724164 (Hba-nol5); EE724167-EE724168 (Hba-W01G7.3); EE724169EE724170 (Hba-arf-1); EE724158-EE724161, EE724188, EE724199, EE7241206-EE7241209 (Hba-rack-1); EE724165-EE724166 (Hba-ben-1); EE724176 (Hba-mrp4); EE724175 (Hba-nhr-47).

\section{Authors' contributions}

T.A. Ciche designed and performed all experiments and wrote the paper. P.W. Sternberg mentored T.A. Ciche during these experiments by providing valuable advice, laboratory space and resources, and edited the paper. Both authors have read and approved the final version.

\section{Additional material}

\section{Additional file 1}

Alignment of $\mathrm{H}$. bacteriophora ESTs to C. elegans genes. Alignments of ESTs used for RNAi to homologs in C. elegans. Bar in A = $300 \mathrm{bp}$ for A$H$ and $600 \mathrm{bp}$ for I and $J$. The panels are genome views from BLASTN analysis of $\mathrm{H}$. bacteriophora ESTs (lower sequences) to the C. elegans genes (upper sequences) using Wormbase [50]. Blocks and lines indicate exons and introns, respectively. A. Hba-W01G7.3 B. Hba-icd-1 (C56C10.8.2) C. Hba-rack-1 (K04D7.1.1), D. Hba-nol-5 (W01B11.3), E. Hba-arf-1 (B0336.2.1), F. Hba-ben-1 (K01G5.7.1), G. Hba-cct-2 (T21B10.7.1), H. Hba-daf-21 (C47E8.5.2), I. Hbamrp-4 (F21G4.2)., J. Hba-nhr-47 (C24G6.4.1).

Click here for file

[http://www.biomedcentral.com/content/supplementary/1471213X-7-101-S1.jpeg]

\section{Additional file 2}

GFP-labeled $\mathrm{P}$. luminescens in $\mathrm{H}$. bacteriophora adult hermaphrodites. $\mathrm{H}$. bacteriophora adult hermaphrodites 80-96 $\mathrm{h}$ after soaking L1s and grown on lawns of GFP-labeled P. luminescens A., B., no dsRNA added, C., D., ds Hba-cct-2 RNA added. $i=$ intestine.

Click here for file

[http://www.biomedcentral.com/content/supplementary/1471213X-7-101-S2.jpeg]

\section{Acknowledgements}

We graciously thank Prof. Ann Burnell (National University of Ireland-Maynooth) for communicating her then unpublished EST data. T.A. Ciche was supported by a fellowship from the Gordon Ross Foundation. Supported by the Howard Hughes Medical Institute, with which P.W. Sternberg is an Investigator.

\section{References}

I. Ciche TA, Darby C, Ehlers R-U, Forst S, Goodrich-Blair H: Dangerous liaisons: The symbiosis of entomopathogenic nematodes and bacteria. Biological Control 2006, 38:22-46.

2. Hallem EA, Rengarajan M, Ciche TA, Sternberg PW: Nematodes, Bacteria, and Flies: A Tripartite Model for Nematode Parasitism. Curr Biol 2007, I 7:898-904.

3. Ciche TA, Ensign JC: For the insect pathogen Photorhabdus luminescens, which end of a nematode is out? Appl Environ Microbiol 2003, 69:1890-1897.

4. Han R, Ehlers RU: Pathogenicity, development, and reproduction of Heterorhabditis bacteriophora and Steinernema carpocapsae under axenic in vivo conditions. J Invertebr Pathol 2000, 75:55-58.

5. Ciche TA, Bintrim SB, Horswill AR, Ensign JC: A Phosphopantetheinyl transferase homolog is essential for Photorhabdus luminescens to support growth and reproduction of the entomopathogenic nematode Heterorhabditis bacteriophora. J Bacteriol 2001, 183:31 I7-3126.

6. Johnigk S-A, Ehlers R-U: Juvenile development and life cycle of Heterorhabditis bacteriophora and $H$. indica (Nematoda: Heterorhabditidae). Nematology 1999, I:25 I-260.

7. Guo S, Kemphues KJ: par-I, a gene required for establishing polarity in C. elegans embryos, encodes a putative Ser/Thr kinase that is asymmetrically distributed. Cell 1995, 8I:6I I-620.

8. Fire A, Xu S, Montgomery MK, Kostas SA, Driver SE, Mello CC: Potent and specific genetic interference by double-stranded RNA in Caenorhabditis elegans. Nature 1998, 391:806-81 I.

9. Tabara H, Grishok A, Mello CC: RNAi in C. elegans: soaking in the genome sequence. Science 1998, 282:430-43I.

10. Kuroyanagi H, Kimura T, Wada K, Hisamoto N, Matsumoto K, Hagiwara M: SPK-I, a C. elegans SR protein kinase homologue, is essential for embryogenesis and required for germline development. Mech Dev 2000, 99:5 I-64.

II. Timmons L, Court DL, Fire A: Ingestion of bacterially expressed dsRNAs can produce specific and potent genetic interference in Caenorhabditis elegans. Gene 200I, 263:103-II 2.

12. Tavernarakis N, Wang SL, Dorovkov M, Ryazanov A, Driscoll M: Heritable and inducible genetic interference by doublestranded RNA encoded by transgenes. Nat Genet 2000, 24: $180-183$

13. Kamath RS, Fraser AG, Dong Y, Poulin G, Durbin R, Gotta M, Kanapin A, Le Bot N, Moreno S, Sohrmann M, et al.: Systematic functional analysis of the Caenorhabditis elegans genome using RNAi. Nature 2003, 421:231-237.

14. Simmer F, Moorman C, van der Linden AM, Kuijk E, van den Berghe PV, Kamath RS, Fraser AG, Ahringer J, Plasterk RH: Genome-wide RNAi of $C$. elegans using the hypersensitive rrf-3 strain reveals novel gene functions. PLoS Biol 2003, I:EI2.

15. Maeda I, Kohara Y, Yamamoto M, Sugimoto A: Large-scale analysis of gene function in Caenorhabditis elegans by high-throughput RNAi. Curr Biol 200I, I I:I7I-I76.

16. Sonnichsen B, Koski LB, Walsh A, Marschall P, Neumann B, Brehm M, Alleaume AM, Artelt J, Bettencourt P, Cassin E, et al:: Full-genome RNAi profiling of early embryogenesis in Caenorhabditis elegans. Nature 2005, 434:462-469.

17. Winston WM, Sutherlin M, Wright AJ, Feinberg EH, Hunter CP: Caenorhabditis elegans Sid-2 is required for environmental RNA interference. Proc Natl Acad Sci USA 2007, I 04: 10565-10570.

18. Leroux MR, Candido EP: Characterization of four new tcp-Irelated cct genes from the nematode Caenorhabditis elegans. DNA Cell Biol 1995, 14:951-960.

19. Bukau B, Horwich AL: The Hsp70 and Hsp60 chaperone machines. Cell 1998, 92:351-366.

20. Gao Y, Thomas JO, Chow RL, Lee GH, Cowan NJ: A cytoplasmic chaperonin that catalyzes beta-actin folding. Cell 1992, 69:1043-1050.

21. Yaffe MB, Farr GW, Miklos D, Horwich AL, Sternlicht ML, Sternlicht $\mathrm{H}$ : TCPI complex is a molecular chaperone in tubulin biogenesis. Nature 1992, 358:245-248.

22. Won KA, Schumacher RJ, Farr GW, Horwich AL, Reed SI: Maturation of human cyclin $E$ requires the function of eukaryotic chaperonin CCT. Mol Cell Biol I998, I 8:7584-7589. 
23. Thulasiraman $V$, Yang CF, Frydman J: In vivo newly translated polypeptides are sequestered in a protected folding environment. Embo J 1999, 1 8:85-95.

24. Kubota $\mathrm{S}$, Kubota $\mathrm{H}$, Nagata K: Cytosolic chaperonin protects folding intermediates of Gbeta from aggregation by recognizing hydrophobic beta-strands. Proc Natl Acad Sci USA 2006 , 1 03:8360-8365.

25. Zhang Y, Ma C, Delohery T, Nasipak B, Foat BC, Bounoutas A, Bussemaker HJ, Kim SK, Chalfie M: Identification of genes expressed in C. elegans touch receptor neurons. Nature 2002, 418:33I-335.

26. Birnby DA, Link EM, Vowels IJ, Tian H, Colacurcio PL, Thomas JH: A transmembrane guanylyl cyclase (DAF-I I) and Hsp90 (DAF2I) regulate a common set of chemosensory behaviors in Caenorhabditis elegans. Genetics 2000, I55:85-104.

27. Inoue T, Takamura K, Yamae H, Ise N, Kawakami M, Tabuse Y, Miwa J. Yamaguchi Y: Caenorhabditis elegans DAF-2I (HSP90) is characteristically and predominantly expressed in germline cells: spatial and temporal analysis. Dev Growth Differ 2003, 45:369-376.

28. Hsu AL, Murphy CT, Kenyon C: Regulation of aging and agerelated disease by DAF- 16 and heat-shock factor. Science 2003, 300: I| 142-1/45

29. McElwee J, Bubb K, Thomas JH: Transcriptional outputs of the Caenorhabditis elegans forkhead protein DAF-16. Aging Cell 2003, 2: III-12|.

30. Murphy CT, McCarroll SA, Bargmann Cl, Fraser A, Kamath RS, Ahringer J, Li H, Kenyon C: Genes that act downstream of DAF16 to influence the lifespan of Caenorhabditis elegans. Nature 2003, 424:277-283.

31. Piano F, Schetter AJ, Morton DG, Gunsalus KC, Reinke V, Kim SK Kemphues KJ: Gene clustering based on RNAi phenotypes of ovary-enriched genes in C. elegans. Curr Biol 2002, I 2:1959-1964.

32. Bloss TA, Witze ES, Rothman JH: Suppression of CED-3-independent apoptosis by mitochondrial betaNAC in Caenorhabditis elegans. Nature 2003, 424: I066-107|.

33. Randazzo PA, Nie Z, Miura K, Hsu VW: Molecular aspects of the cellular activities of ADP-ribosylation factors. SCi STKE 2000 59:REI.

34. Driscoll M, Dean E, Reilly E, Bergholz E, Chalfie M: Genetic and molecular analysis of a Caenorhabditis elegans beta-tubulin that conveys benzimidazole sensitivity. I Cell Biol 1989, 109:2993-3003.

35. Rual JF, Ceron J, Koreth I, Hao T, Nicot AS, Hirozane-Kishikawa T, Vandenhaute J, Orkin SH, Hill DE, van den Heuvel S, Vidal M: Toward improving Caenorhabditis elegans phenome mapping with an ORFeome-based RNAi library. Genome Res 2004, 14:2162-2|68

36. Gonczy P, Echeverri C, Oegema K, Coulson A, Jones SJ, Copley RR, Duperon J, Oegema J, Brehm M, Cassin E, et al.: Functional genomic analysis of cell division in C. elegans using RNAi of genes on chromosome III. Nature 2000, 408:33I-336.

37. Richardson $\mathrm{WH}$, Schmidt TM, Nealson $\mathrm{KH}$ : Identification of an anthraquinone pigment and a hydroxystilbene antibiotic from Xenorhabdus luminescens. Appl Environ Microbiol 1988 54:1602-1605.

38. Ciche TA, Blackburn M, Carney JR, Ensign JC: Photobactin: A catechol siderophore produced by Photorhabdus luminescens, an entomopathogen mutually associated with Heterorhabditis bacteriophora NCI nematodes. Appl Environ Microbiol 2003, 69:4706-47|3.

39. Broeks A, Gerrard B, Allikmets R, Dean M, Plasterk RH: Homologues of the human multidrug resistance genes MRP and MDR contribute to heavy metal resistance in the soil nematode Caenorhabditis elegans. Embo J 1996, 15:6132-6143.

40. Novillo A, Won S-J, Li C, Callard IP: Changes in Nuclear Receptor and Vitellogenin Gene Expression in Response to Steroids and Heavy Metal in Caenorhabditis elegans. Integr Comp Biol 2005, 45:6I-7I.

41. Winston WM, Molodowitch C, Hunter CP: Systemic RNAi in C. elegans requires the putative transmembrane protein SID-I. Science 2002, 295:2456-2459.

42. Feinberg EH, Hunter CP: Transport of dsRNA into cells by the transmembrane protein SID-I. Science 2003, 30 I: I545-I 547.
43. Sandhu SK, Jagdale GB, Hogenhout SA, Grewal PS: Comparative analysis of the expressed genome of the infective juvenile entomopathogenic nematode, Heterorhabditis bacteriophora. Mol Biochem Parasitol 2006, 145:239-244.

44. Timmons $L$, Fire $A$ : Specific interference by ingested dsRNA. Nature 1998, 395:854-854.

45. Geldhof P, Visser A, Clark D, Saunders G, Britton C, Gilleard J, Berriman $M$, Knox $D$ : RNA interference in parasitic helminths: current situation, potential pitfalls and future prospects. Parasitology 2007: I-I I.

46. Kimber MJ, McKinney S, McMaster S, Day TA, Fleming CC, Maule AG: flp gene disruption in a parasitic nematode reveals motor dysfunction and unusual neuronal sensitivity to RNA interference. Faseb J 2007.

47. Nugent MJ, O'Leary SA, Burnell AM: Optimised procedures for the cryopreservation of different species of Heterorhabditis. Fundamental \& Applied Nematology 1996, 19: 1-6.

48. Brenner S: The genetics of Caenorhabditis elegans. Genetics 1974, 77:7I-94

49. Altschul SF, Gish W, Miller W, Myers EW, Lipman DJ: Basic local alignment search tool. J Mol Biol I990, 21 5:403-4I0.

50. Schwarz EM, Antoshechkin I, Bastiani C, Bieri T, Blasiar D, Canaran P Chan J, Chen N, Chen WJ, Davis P, et al.: WormBase: better software, richer content. Nucleic Acids Res 2006, 34:D475-478.

51. Rozen S, Skaletsky H: Primer3 on the WWW for general users and for biologist programmers. In Bioinformatics Methods and Protocols: Methods in Molecular Biology Edited by: Krawetz S, Misener S. Totowa, NJ: Humana Press; 2000:365-386.

52. Chan JW, Goodwin PH: Extraction of genomic DNA from extracellular polysaccharide-synthesizing gram-negative bacteria. Biotechniques 1995, 18:418-422.

53. Fraser AG, Kamath RS, Zipperlen P, Martinez-Campos M, Sohrmann $M$, Ahringer J: Functional genomic analysis of $C$. elegans chromosome I by systematic RNA interference. Nature 2000, 408:325-330.

Publish with BioMed Central and every scientist can read your work free of charge

"BioMed Central will be the most significant development for disseminating the results of biomedical research in our lifetime. "

Sir Paul Nurse, Cancer Research UK

Your research papers will be:

- available free of charge to the entire biomedical community

- peer reviewed and published immediately upon acceptance

- cited in PubMed and archived on PubMed Central

- yours - you keep the copyright 